\title{
Crack Propagation under Variable Amplitude Loading
}

\author{
Miloudi Abdelkader, Zemri Mokhtar ${ }^{\mathrm{a}}$, Benguediab Mohamed ${ }^{\mathrm{a} *}$ \\ Mazari Mohamed $^{\mathrm{a}}$, Amrouche Abdelwaheb ${ }^{\mathrm{b}}$ \\ ${ }^{a}$ Laboratory and Reactive Systems, Department of Mechanical Engineering, \\ Djillali Liabes University of Sidi Bel Abbes, Sidi Bel Abbes, Algeria \\ ${ }^{\mathrm{b}}$ Laboratory of Civil Engineering and Geo-Environment LGCgE, Faculty of Applied Sciences, \\ Artois University, Béthune, France
}

Received: May 29, 2012; Revised: April 26, 2013

\begin{abstract}
Experience shows that a damage induced by a given cycle is dependent on the loading history. In this regard, the objective of this paper is to study and describe the phenomenology of the loading history on crack propagation. Different loading configuration has been considered for fatigue crack propagation of XC38 steel; overload cycles followed by underload and vice versa were considered during propagation. Measure of crack opening has been made using compliance method. It is shown that the main parameters which cause retardation are the residual compressive stresses and the crack closure. The finite element modeling is used to calculate the evolution of residual stress profiles before and after application of the overload-underload cycle. It corroborates the hypotheses on the mechanisms behind, including those proposed on the residual stresses at the crack tip.
\end{abstract}

Keywords: crack, overload, underload, plastic zone, residual stress

\section{Introduction}

Maintenance service in aeronautics, transports, machines and installations often face the existence and appearance of cracks in metal components of their structures subjected to a cyclic loading with variable amplitude. In fatigue, loading history is one of the main factors for calculating the number of cycle to rupture $\mathrm{N}_{\mathrm{r}}$ of cracked element. The interaction of the loading level influences the crack growth rate. The understanding of the effect of loading history under the spectrum necessitated to consider a simple loading with respect to real spectrum.

It is obvious that the application of an overload during crack propagation leads to a crack growth rate decreasing and in certain cases to arrest. This effect increases the life time of the structure.

The effect of an underload cycle after overloading cycle has not been a topic of many works ${ }^{1-10}$. It is clear that an underload cycle modifies the retardation characteristics. The present paper is a continuation to this works. Many authors ${ }^{11-18}$ have shown that the retardation does not depend exclusively on microstructure changes due to overload or on the plastic zone geometry, but rather it depends on residual stress associated with plastic deformation currently, it is believed that residual stress and crack closure with the change of plastic due to overload are the main causes of retardation from this point crack point opening measurements are made to put into evidence the beneficial effect of residual stresses. This work presents a study of the influence of an overload cycle followed by an underload and vice-versa during fatigue crack growth for the case of XC38.

*e-mail: benguediab_m@yahoo.fr

\section{Experimental Procedure}

The material used for this study is an XC38 steel used in molding, transmission shifts and tooling components.

The chemical and mechanical characteristics are given in Table 1 and Table 2.

All tests were conducted on CT75 specimens with a thickness $\mathrm{B}=4 \mathrm{~mm}$ and width $\mathrm{W}=75 \mathrm{~mm}$.

All the cracking tests were carried out under air and at room temperature on a servo-hydraulic machine type, INSTRON 8516 with static capacity of $\pm 50 \mathrm{KN}$ and dynamic of $\pm 100 \mathrm{KN}$.

To quantify the overload and underload effect on crack propagation four types of loadings have been applied (Figure 1). All tests whose results were used in this study are shown in Table 3.

The rate of overload $\tau_{\text {ouv }}$ and rate underload $\tau_{\text {und }}$ can be defined by the following equations respectively:

$$
\begin{gathered}
\tau_{\text {ouv }}=\frac{K_{\text {ouv }}-K_{\min }}{K_{\max }-K_{\min }} \\
\tau_{\text {und }}=\frac{K_{\min }-K_{\text {und }}}{K_{\max }-K_{\min }}
\end{gathered}
$$

\section{Analysis of Results}

\subsection{Evolution of crack length with the number of cycle $N$}

Figure 2 illustrates the different possible cases of fatigue loading shown as a curve giving the evolution of crack length (a) with the number of cycle $(\mathrm{N})$. 
For a simple overload it is observed three different domains:

In stage one the crack advance with increasing number of cycle N. The second stage corresponds on the application of overload, the crack shows down for a certain number of cycle Nd called number of delay cycles. After the end of the overloads effect, the crack advances normally.

In the case of an overloads followed by underload when $\mathrm{P}_{\text {under }}=\mathrm{P}_{\max }$ for an overload ratio $\tau=1.7$ it is observed a decrease in retardation effect.

For a good comprehension of underload effect, we decided to make tests by varying the peak of underload as a function of the load when $\mathrm{P}_{\text {under }}=\mathrm{P}_{\text {peak }}$. It is noticed that the application of a high underload following an overload decreases significantly the number of delay cycles $\mathrm{N}_{\mathrm{d}}$.

Table 1. Chemical composition of XC 38.

\begin{tabular}{cccccc}
\hline Element & $\mathbf{C}$ & $\mathbf{M n}$ & $\mathbf{S i}$ & $\mathbf{P}$ & $\mathbf{S}$ \\
\hline$\%$ & 0.38 & 0.65 & 0.25 & 0.01 & 0.02 \\
\hline
\end{tabular}

Table 2. Mechanical properties of CX 38.

\begin{tabular}{cccccc}
\hline $\mathbf{E}$ & $\begin{array}{c}\mathbf{R e}_{\mathbf{0 . 2}} \boldsymbol{\%} \\
\mathbf{G P a}\end{array}$ & $\begin{array}{c}\mathbf{R m} \\
\mathbf{M P a}\end{array}$ & $\begin{array}{c}\mathbf{A} \\
\mathbf{\%}\end{array}$ & $\mathbf{H v}$ & $\mathbf{Y}$ \\
\hline 212 & 315 & 580 & 20 & 210 & 0.3 \\
\hline
\end{tabular}

Table 3. Different types of loadings.

\begin{tabular}{|c|c|c|c|c|}
\hline Material & $\begin{array}{c}\text { Type of } \\
\text { tests }\end{array}$ & Ratio R & $\begin{array}{l}\text { Overload } \\
\text { ratio }\end{array}$ & $\begin{array}{l}\text { Underload } \\
\text { ratio }\end{array}$ \\
\hline XC38 & $\begin{array}{c}\text { Single } \\
\text { overload }\end{array}$ & 0.1 & 1.7 & 1 \\
\hline XC38 & Overload/ & 0,1 & 1.70 & -1.11 \\
\hline XC38 & underload & 0,1 & 1.70 & -1.70 \\
\hline XC38 & $\begin{array}{c}\text { Underload/ } \\
\text { overload }\end{array}$ & 0,1 & 1.70 & -1.70 \\
\hline
\end{tabular}
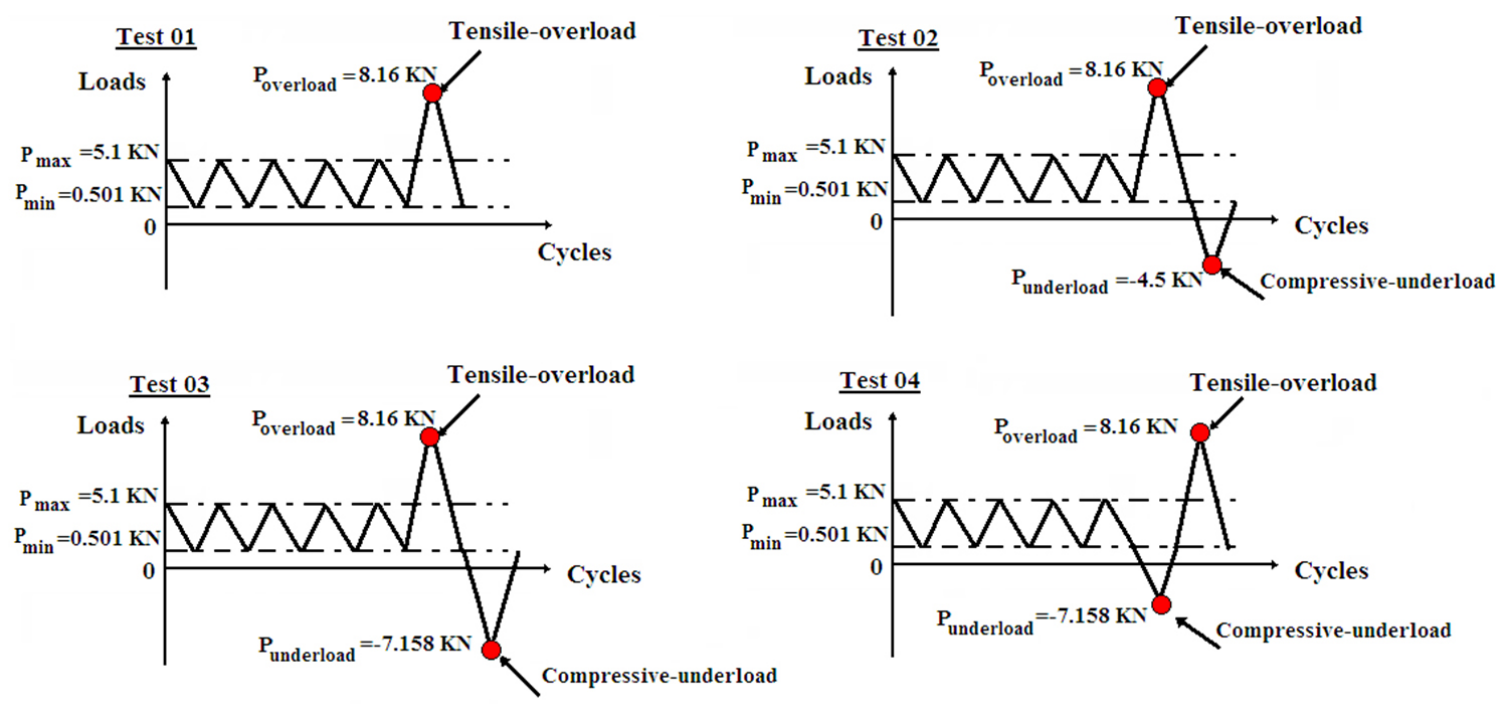

Figure 1. different types of loadings.
Furthermore, in the case of a high underload in compression applied before an overload $\left(\mathrm{P}_{\text {uneder }}=\mathrm{P}_{\text {peak }}\right)$ attenuates the delay of crack propagation.

\subsection{Evolution of crack growth rate da/dN as a function of stress intensity factor amplitude $\Delta K$}

In Figure 3, we propose to study the phases of crack growth. It illustrates the evolution of the crack growth rate $\mathrm{da} / \mathrm{dN}$ as a function of the amplitude of the stress intensity factor $\Delta \mathrm{K}$. we note that after the application of an overload, there is a crack arrest for a certain number of cycles corresponding to retardation cycles $\mathrm{N}_{\mathrm{d}}$.

In terms of growth rate, this phenomenon results in instantaneous appearance of a "hook" putting into evidence deceleration, which corresponds to an immediate delay.

The crack growth rate after an overload can be described by two stages:

- When the growth rate decreases rapidly to reach a minimum value noted $(\mathrm{da} / \mathrm{dN})_{\min }$ this zone highly perturbed by the overload corresponds to a crack length $\mathrm{a}_{\min }$;

- The crack progresses in the plastic zone until it reaches its initial value $(\mathrm{da} / \mathrm{dN})_{\text {base }}$

It should be noted here, that the low value of crack growth rate reached in the case of an overload for a ration $\tau=1.7$, the minimum growth rate is about de 2.16 $10-5 \mathrm{~mm} /$ cycle while its value $1.2 e-4 \mathrm{~mm} /$ cycle in the case of an overload following by an underload where $\mathrm{P}_{\text {under }}=\mathrm{P}_{\text {peak }}$. The growth rate increases when the ration of underload increases its value becomes $1.36 e-4 \mathrm{~mm} / \mathrm{cycle}$.

In this case, this high-intensity underload applied after an overload $\left(\mathrm{P}_{\text {under }}=\mathrm{P}_{\text {peak }}\right)$ two important phenomena re produced:

- After the application of an overload followed by an underload the crack growth rate decreases slightly;

- It reaches a growth rate higher than its initial growth rate then reaches a gain its initial growth after a certain number of cycles. 
This can be explained by the residual tensile stresses induced by high applied underload.

With a high underload applied before an overload (when $\mathrm{P}_{\text {under }}=\mathrm{P}_{\text {peak }}$ ) eliminates the retardation of crack propagation.

Table 4 summarizes the different results for different loading type to show the difference in behavior betweens thesis loadings.

\subsection{Analysis in terms of crack closure}

To measure the opening load $\mathrm{P}_{\mathrm{o}}$ a strip sensor has been used. The principle is to measure the deformation of the ligament of a specimen, in effect; this deformation is linked to its rigidity. The latter is weakened when the crack

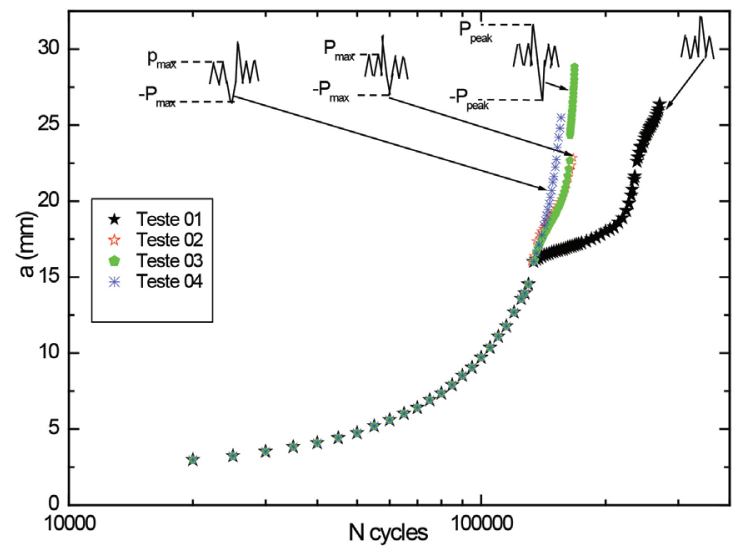

Figure 2. Evolution of crack length (a) with cycle number (N).

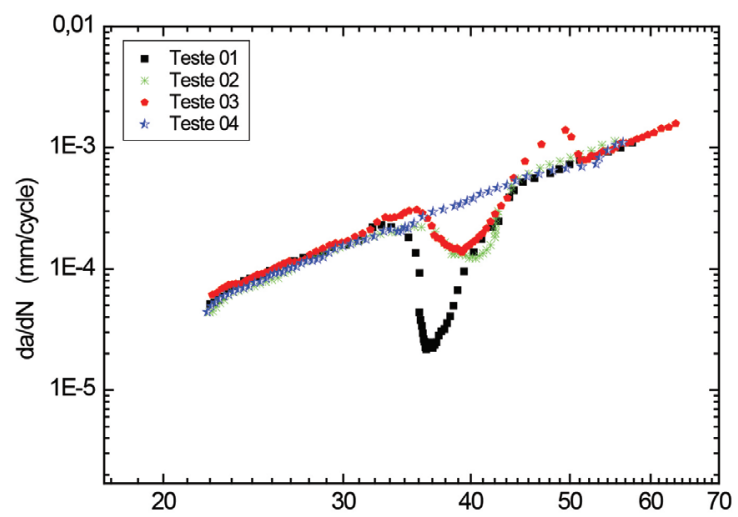

Figure 3. Evolution of growth rate $\mathrm{da} / \mathrm{dN}$ as a function of SIF amplitude $\Delta \mathrm{K}$.

Table 4. Results for different types of loadings.

\begin{tabular}{lccc}
\hline \multicolumn{1}{c}{ Types of loading } & $\begin{array}{c}\boldsymbol{N}_{\boldsymbol{d}} \\
(\text { cycles })\end{array}$ & $\begin{array}{c}\boldsymbol{a}_{\boldsymbol{d}} \\
(\mathbf{m m})\end{array}$ & $\begin{array}{c}(\text { da/dN })_{\min } \\
(\mathbf{m m} / \text { cycles })\end{array}$ \\
\hline $\begin{array}{l}\text { Single overload } \\
\text { Overload/underload } \\
\left(\mathbf{P}_{\text {under }}=\mathbf{P}_{\max }\right)\end{array}$ & 94000 & 7,49 & $2,16 E-5$ \\
$\begin{array}{l}\text { Overload/underlod } \\
\left(\mathbf{P}_{\text {under }}=\mathbf{P}_{\text {peak }}\right)\end{array}$ & 25000 & 6,34 & $1,2 E-4$ \\
$\begin{array}{l}\text { Underload/overload } \\
\left(\mathbf{P}_{\text {under }}=\mathbf{P}_{\text {max }}\right)\end{array}$ & 0 & 6,09 & $1,36 E-4$ \\
\hline
\end{tabular}

progresses. Moreover, when the phenomenon of crack closure occurs, the load-strain curve $P$ - $\delta$ shows a change in slope Figure 4.

During the crack propagation, there is the appearance of two distinct bridges on diagrams $(\mathrm{P}-\delta)$, corresponding apparently to double opening Figures 5, 6 and 7.

This double opening point was obtained regardless of the position relative to the overload of underload.

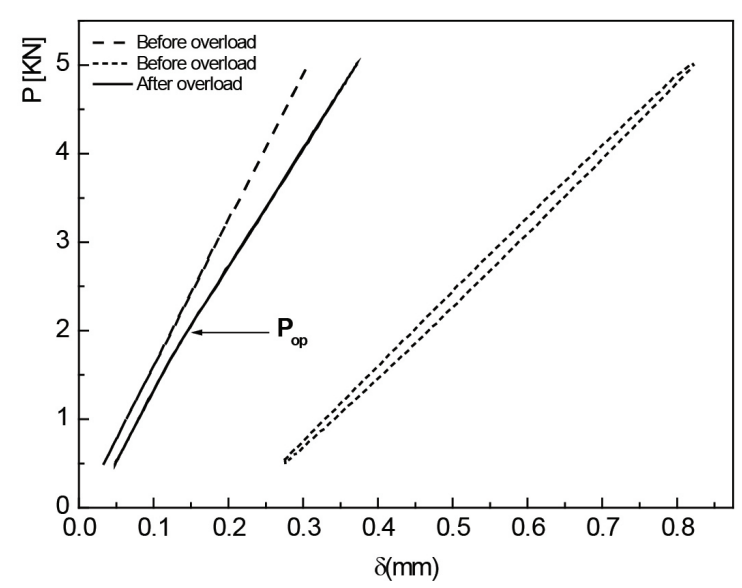

Figure 4. Evolution of hysteresis cycle $P-\delta$ load-strain.

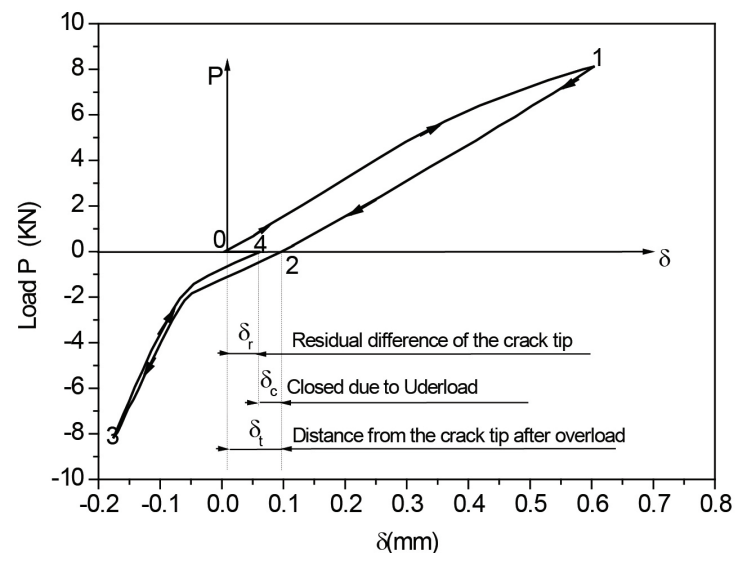

Figure 5. Evolution of hysteresis cycle $P-\delta$ load-strain (test 02 ).

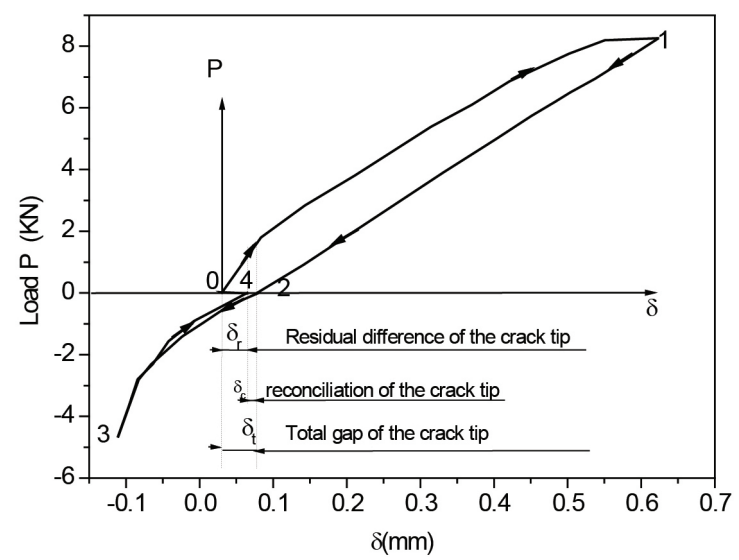

Figure 6. Evolution of hysteresis cycle $P-\delta$ load-strain (test 03 ). 


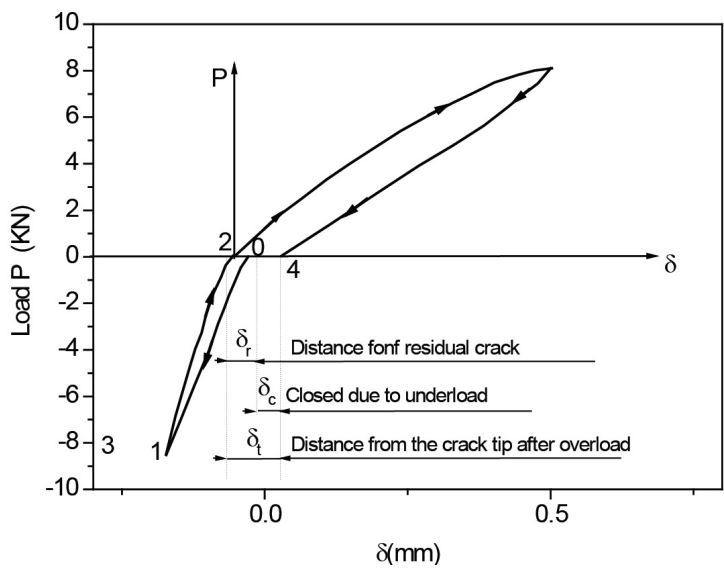

Figure 7. Evolution of hysteresis cycle $P$ - $\delta$ load-strain (test 04 ).

The existence of this second opening point on the diagram $(\mathrm{P}-\delta)$ does have the measures in question the first point of opening. This first point is the notion of opening point according to Elber.

On the diagrams $(\mathrm{P}-\delta)$, we determine following displacements:

- The total displacement of the $\delta$ crack tip;

- Displacement created by the underload $\delta_{c}$;

- The residual displacement $\delta_{\mathrm{r}}$ remaining after the sequence overload.

It is observed that the residual displacement of the sequence-underload-overload is greater than the residual displacement of the sequence of overload-underload.

We also note that when the rate of underload increases, the value of the distance from the crack tip residual decreases. This effect tends to give back to the initial crack acuity, resulting in a decrease in life time.

\subsection{Evolution of tensile opening}

In this study, changes in opening tress distribution have been taken into account in the calculation of the stress intensity factor for each loading case. We observe that after applying an overload the tensile opening stress increase rapidly and reach a greater value than that of the base load then slowly decrease (Figure 8a).

An overload applied before underload, causing a decrease of the stress of opening, which is less than the maximum stress followed by a slow decrease to a level below the previous case (Figure $8 \mathrm{~b}$ ).

In Figure $8 \mathrm{c}$ it is observed that after the application of an underload be a decrease in tensile opening load is high with a higher underload ratio.

Figure 9 shows the plot of the variation of the opening stress intensity factor $K_{o p}$ with respect to crack length $a$, the results show that there are distinct stages:

- Effect of single overload

In stage one where the loading is of constant amplitude represents an increasing effective stress intensity factor $\Delta \mathrm{K}_{\text {eff }}$ due to a constant opening load $\mathrm{P}$.

The second stage corresponds to the application of a first overload cycle where the crack progresses in a plastic zone
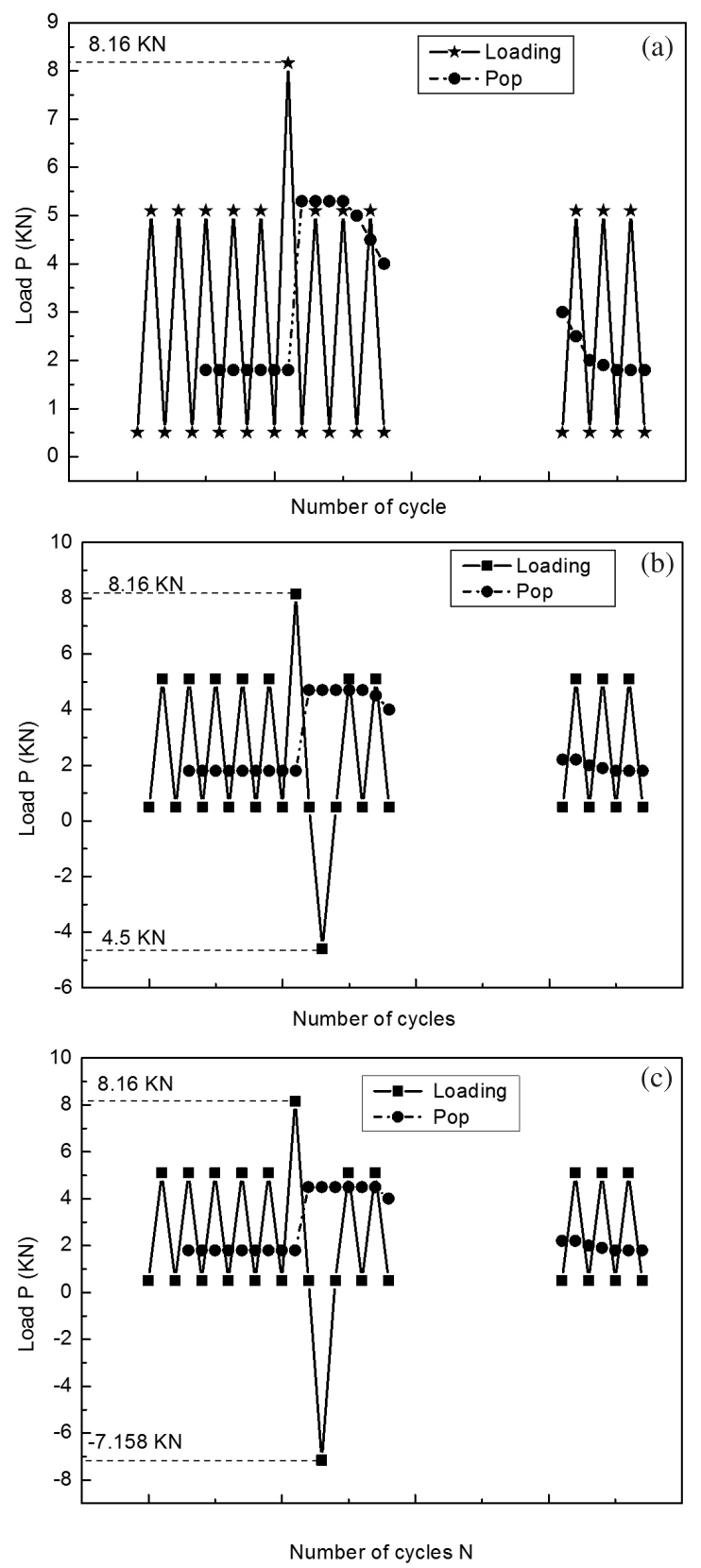

Figure 8. a) Variation of opening load after overload; b) Variation of opening load after overload/underload $\left(\mathrm{P}_{\text {under }}=\mathrm{P}_{\text {max }}\right)$; c) Variation of opening load after overload/underload $\left(\mathrm{P}_{\text {under }}=\mathrm{P}_{\text {peak }}\right)$.

layer than that associated to the highest load (overload). The required opening stress increases and causes a diminution of $\Delta K_{\text {eff }}$ The reduction of the effective stress intensity factor explains the decrease after the application of overload, which gives an immediate delay.

The third stage, the opening stress decreases gradually with a growth that follows until a new equilibrium value is reached.

- Effect of an overload followed by an underload

In the case of an overload followed by an underload the crack closure occurs just after the application of an overload 
followed by underload. This takes place at a distance of $4 \mathrm{~mm}$, which may be comparable to the overage values of crack length associated which the minimum distance of propagation after overload/underload. The increase of underload amplitude lowers the opening stress intensity factor.

- Effect of an underload followed by overload

In the case of high underload applied before an overload $\left(\mathrm{P}_{\text {under }}=\mathrm{P}_{\text {pic }}\right)$ the opening stress intensity factor is low. This can be explained by the residual tensile stress due to the applied underload.

We find that if the tensile overload is followed by a compressive overload, the material at the crack tip may undergo reverse plastic deformation and this reduces the residual stresses.

Figure 10 shows the evolution of crack closure $(U)$ as a function of crack length $(a)$. The value of this ration $U$ permit to deduce the amplitude of the effective stress intensity factor $\Delta K_{\text {eff }}$ and this predict the crack growth rate using Elber's relation.

The opening ratio $U$ can be expressed by the following equation:

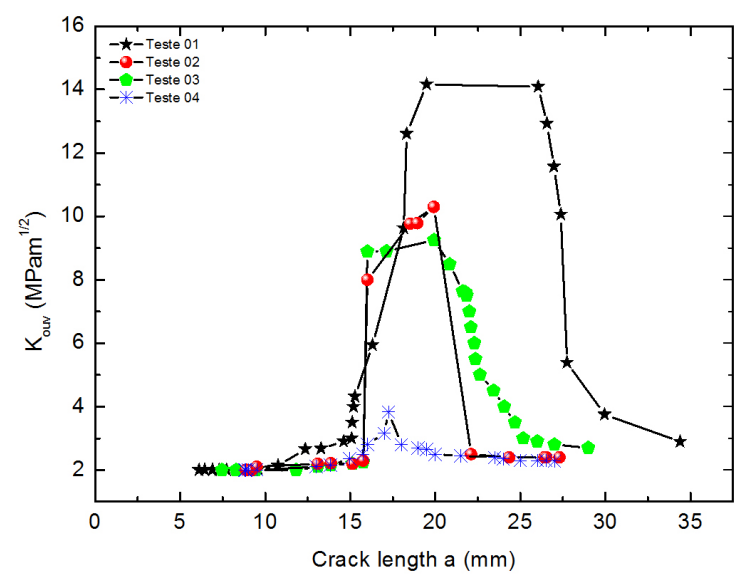

Figure 9. Evolution of the opening stress intensity $K_{o p}$ factor with crack length $a$.

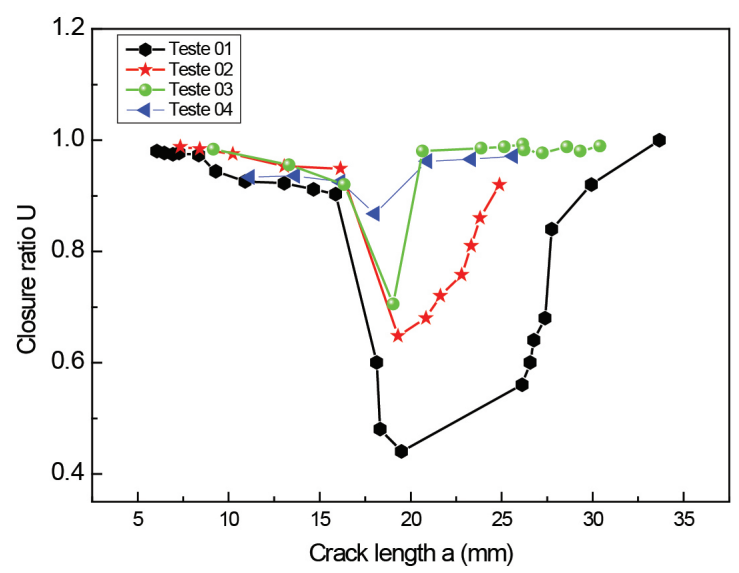

Figure 10. Evolution of closure relation with crack length (a).
$U=\frac{\Delta K_{e f f}}{\Delta K}$

The effective stress intensity factor range is given by the equation:

$\Delta K_{\text {eff }}=K_{\max }-K_{\text {ouv }}=U . \Delta K$

\subsection{Evolution of the micro-hardness}

Micro-hardness measurements were performed using an indenter type ZWICK ZHV1 (a diamond in the form of a square-based pyramid whose opposite faces form an angle of $136^{\circ}$ ), Around 30 indentations near fatigue crack growth path were made. The distance between the centers of two adjacent indentations is about $0.9 \mathrm{~mm}$. All the hardness readings were obtained using $2 \mathrm{~kg}$-force load, and the full load was held for $15 \mathrm{~s}$. the positions of the measuring points of hardness are given in Figure 11.

Figure 12 shows the micro-hardness profile measured on the surface of specimens from the figure on can state that:

The cyclic hardening more important results in a significant increase of micro hardness just after the application of an overload cycle. This reduces the growth rates in this zone perturbed by the overload resulting in retardation.

The hardening rate looks very important in the case of overload which provokes a consequential retardation. If the

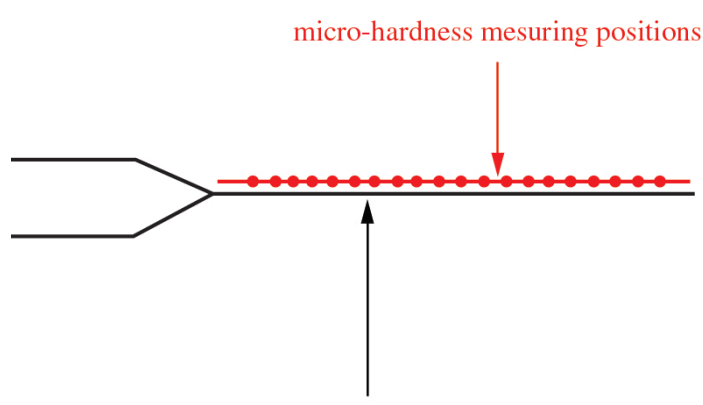

fatigue crack patch

Figure 11. Micro-hardness measuring positions.

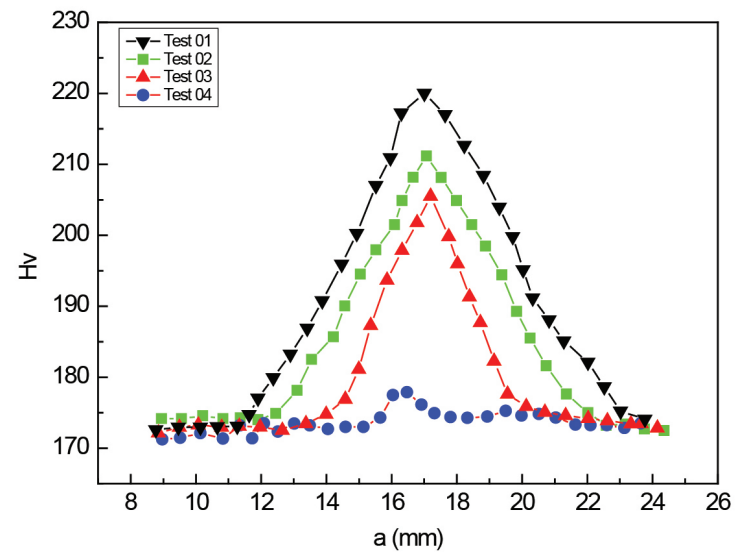

Figure 12. Micro-hardness profile measured on the surface of specimens. 
tensile overload is followed by a compressive overload, the hardening intensity is less with respect to a single overload.

For the same case, the intensity decreases with the hardening ration overload. Contrary to the behavior observed tensile overload followed by a compression load, the intensity of curing is less important.

\section{Numerical Simulation}

It is believed that residual stresses and crack closure which one both related to plastic zone development due to overload are most of the time the cause of the retardations. These two phenomena will be affected by monotonic and cyclic hardening in the crack tip zone. It is worth introducing residual stress and crack closure concepts.

Residual stresses have an important role in the retardation mechanism after overload cycle, overload / underload and underload/overload.

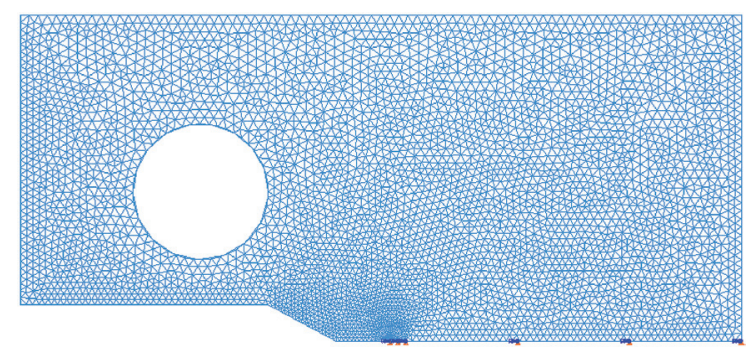

Figure 13. Mesh of the half specimen CT.

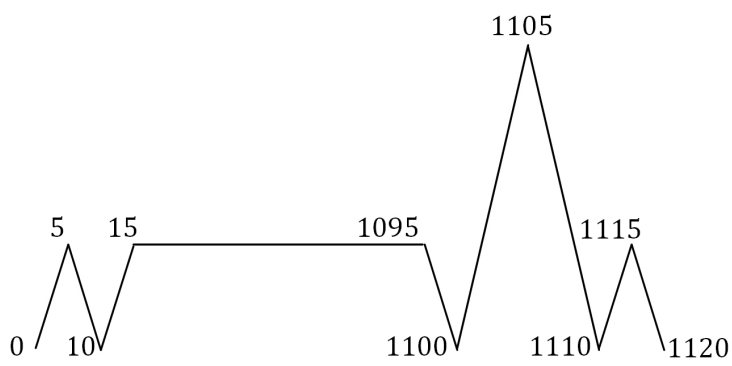

Figure 14. Steps of loading applied to the numerical modeling (single overload).

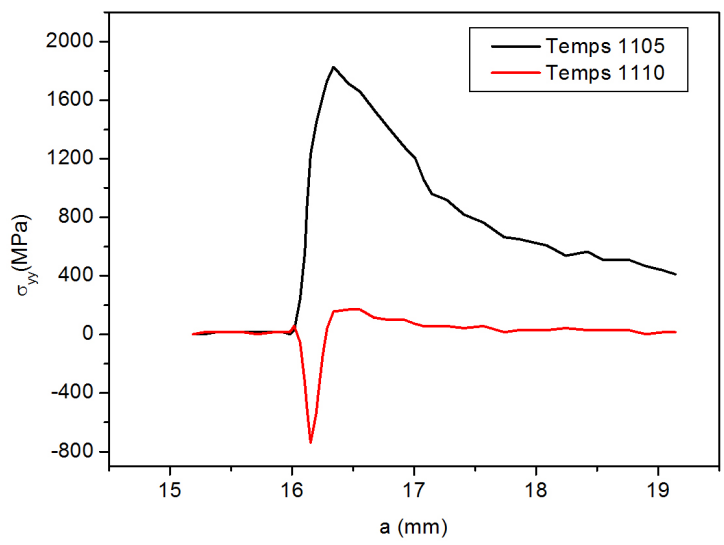

Figure 15. Evolution of stress field during the overload.

\subsection{Conditions modeling}

The aim of this section is to perform a numerical simulation of crack propagation advance. This has been conducted using ANSYS. The geometric dimension are similar to those of the specimen used in the experimental study ( $\mathrm{w}=75 \mathrm{~mm}, \mathrm{~B}=4 \mathrm{~mm}$ ). In the simulation, the properties and behavior of the material determined by experimental monotonic tests were used. For symmetry reason only onehalf of the specimen has been meshed Figure 13.

We used triangular elements with 3 nodes; the size of elements in the path of the crack is $0.1 \mathrm{~mm}$. The advance of the crack for $0.1 \mathrm{~mm}$ is performed represented 10 increments for a crack length for $0-25 \mathrm{~mm}$.

The boundary conditions are:

- The load is applied on the upper pact of the hole;

- The node displacement $\left(\mathrm{U}_{\mathrm{y}}\right)$ locates en front of the crack are blocked;

- The crack advance, simulated by kill-element technique, the number indicates "increment" required to reach this point $0.1 \mathrm{~mm}$ crack advance is made every five increments.

\subsection{Evolution of the stress field}

In this part, we represent the stress distribution for the different cases studied. It is noticed the common profile

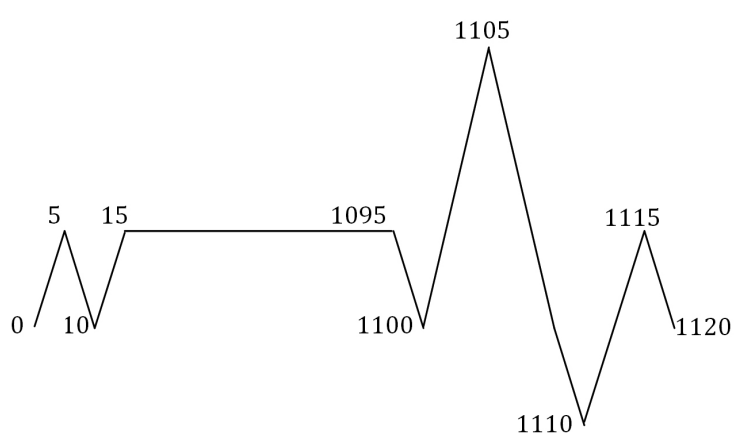

Figure 16. Steps of loading applied to the numerical modeling (overload/underload).

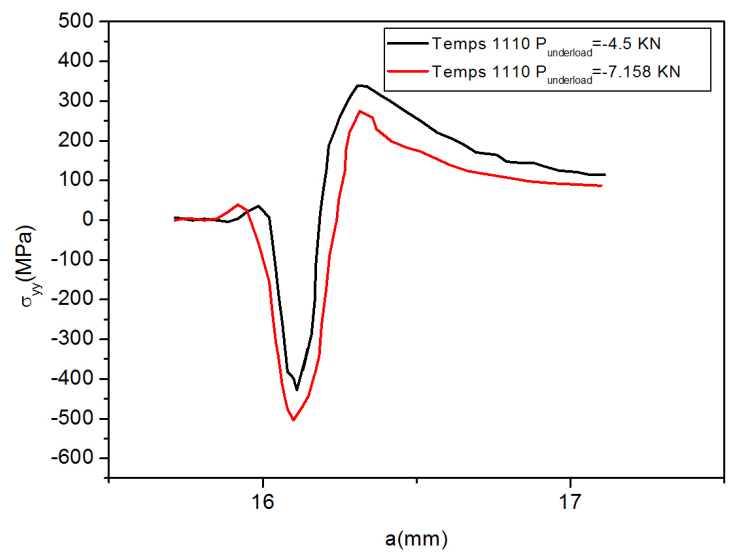

Figure 17. Evolution of stress field during overload-underload (Time 1110). 


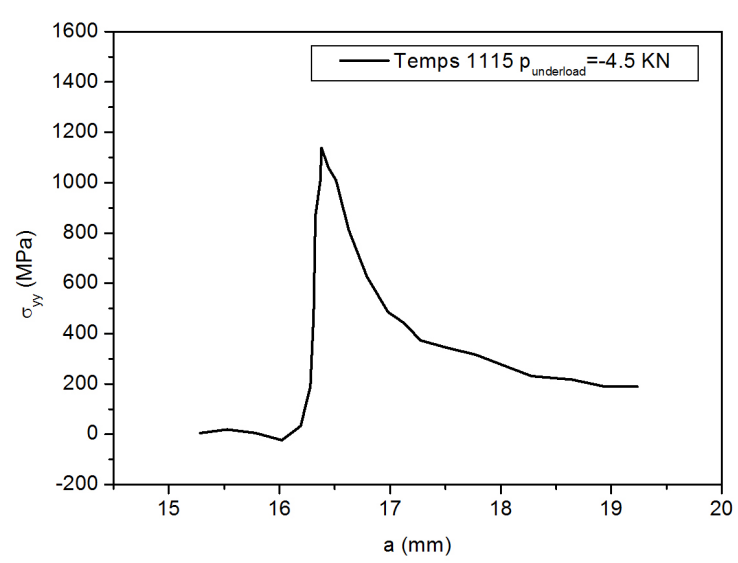

Figure 18. Evolution of stress field during overload-underload (Time 1115).

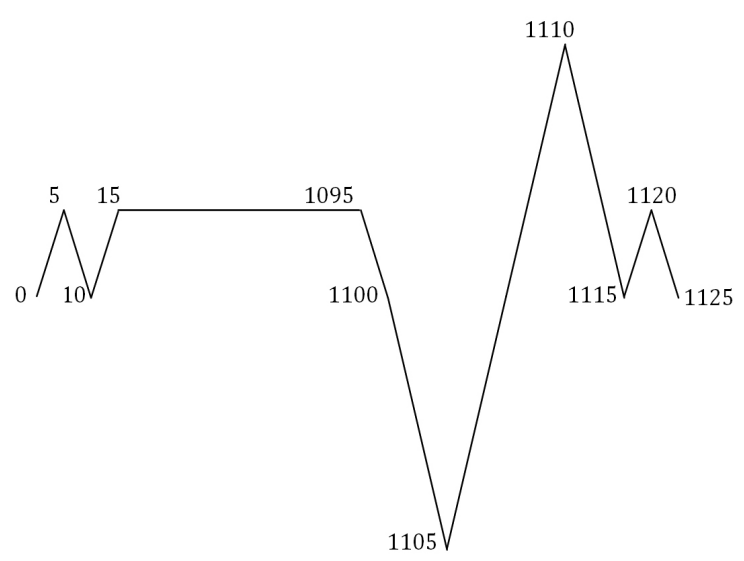

Figure 19. Steps of loading applied to the numerical modelling (underload/overload).

of бyy during overload cycle and overload/underload followed by underload and vice-versa. During overload cycle Figure 14 it is observed an increase compressive stresses (the increment 1105 that represents the propagation cycle at the time of application of the overload), which are added to opening stresses resulting from unloading this delaying the opening of the crack Figure 15.

If an underload cycle followed by an overload cycle Figure 16 (the increment 1110 that represents the propagation cycle at the time of application of the underload) residual stresses exist at crack tip but are less important with respect to a single overload. It is noticed that for an undreload applied after an overload decreases considerably residual stresses Figure 17.

In order to investigate the effect of an underload, the underload ratio has been increased Figure 18. It is observed

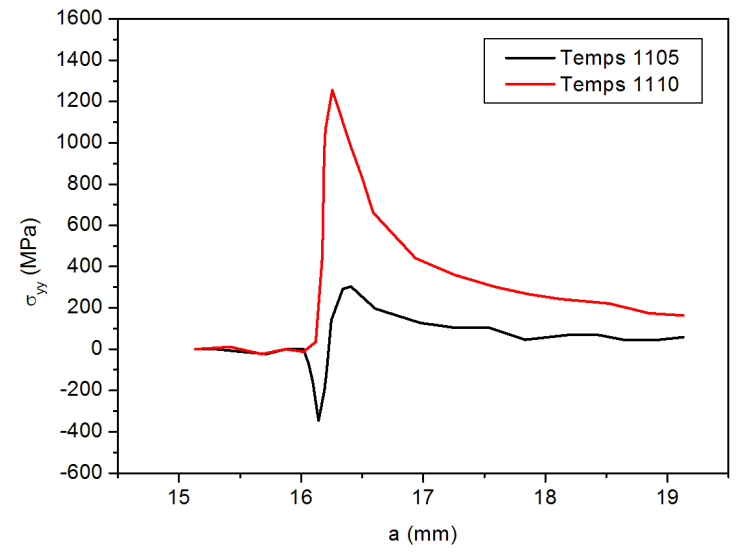

Figure 20. Evolution of stress field during underload/ Overload.

that the higher the overload the lower is the values of compressive stresses this leads to the acceleration of the crack propagation.

The effect of high underload has also been investigated Figure 19. It is noticed the application of high underload provokes a relaxation of compressive residuals stresses at the crack tip, if the applied compressive stress during underload is higher, when underload the residual stress become a tensile this will accelerates the crack propagation and eliminates the retardation Figure 20.

\section{Conclusion}

The study presented in this paper aims to characterize the crack propagation under variable loading. In this case, all the cycles are either an overload/underload or underload/ overload type.

The study has focused primarily on the influence of both the overload underload ratios. Four types of loading configurations were experimentally tested for the case of XC 38 steel. Through the experimental investigation, we find that for simple overload applied during constant amplitude loading causes a delay in crack propagation. Crack closure is important in the case of single overload.

If the tensile overload is followed by a compressive overload decreases the number of delay cycles, the material at the crack tip may undergo reverse plastic deformation and this reduces the residual stresses.

The application of a high underload following an overload decreases significantly the number of delay cycles $\mathrm{N}_{\mathrm{d}}$. In this case the Crack closure is less important for the case of overload/underload than that of single overload.

We can conclude that the life time caused by a sequence of overload-underload and lower than that caused by simple overload.

The measurements show that the residual compressive stresses and the crack closure are the major's causes of delay. 


\section{References}

1. Decoopman X. Influence des conditions de chargement sur le retard à la propagation d'une fissure de fatigue après l'application d'une surcharge. [Thèse]. Lille: Lille University of Science and Technology; 1999.

2. Fonte M, Romeiro F and Freitas M. Environment effects and surface roughness on fatigue crack growth at negative R-ratios. International Journal of Fatigue. 2007; 29:1971-1977. http:// dx.doi.org/10.1016/j.ijfatigue.2007.02.027

3. Beden SM and Abdullah S. Fatigue crack growth simulation of aluminium alloy under spectrum loadings. Materials and Design. 2010; 31: 3449-3456. http://dx.doi.org/10.1016/j. matdes.2010.01.039

4. Pommier S. A study on the relationships between variable amplitude fatigue crack growth and the cyclic constitutive behavior of an alloy. International Journal of Fatigue. 2001; 23:111-118. http://dx.doi.org/10.1016/S01421123(01)00165-7

5. Romeiro F, Freitas M and Pommier S. Effect of overloads and underloads on fatigue crack growth and interaction effects. International Journal of Fatigue. 2009; 31:1189-1894. http:// dx.doi.org/10.1016/j.ijfatigue.2009.01.001

6. Dabayeh A and Topper T. Changes in crack-opening stress after underloads and overloads in 2024-T351 aluminium alloy. International Journal of Fatigue. 1995; 17:261-269. http:// dx.doi.org/10.1016/0142-1123(95)00010-Q

7. Rui B and Xiang Z. Fatigue crack growth behaviour and life prediction for 2324-T39 and 7050-T7451 aluminium alloys under truncated load spectra. International Journal of Fatigue. 2010; 32:1180-1189. http://dx.doi.org/10.1016/j. ijfatigue.2009.12.010

8. Makabe C, Purnowidodo A and McEvily AJ. Effects of surface deformation and crack closure on fatigue crack propagation after overloading and underloading. International Journal of Fatigue. 2004; 26:1341-1348. http://dx.doi.org/10.1016/j. ijfatigue.2004.03.017

9. Silva FS. Fatigue crack propagation after overloading and underloading at negative stress ratios. International Journal of Fatigue. 2007; 29:1757-1771. http://dx.doi.org/10.1016/j. ijfatigue.2007.03.012
10. Skorupa M. Load interaction effects during fatigue crack growth under variable amplitude loading. Fatigue \& Fracture of Engineering Materials \& Structures. 1999; 22:905-926. http:// dx.doi.org/10.1046/j.1460-2695.1999.00158.x

11. Bacila A. Influence des effets de surcharges et souscharges sur la propagation d'une fissure de fatigue. Modélisation et estimation de la durée de vie des éléments de construction mécanique. [Thèse]. Lille: Lille University of Science and Technology; 2007.

12. Fleck NA, Shin CS and Smith RA. Fatigue crack growth under compressive loading. Engineering Fracture Mechanics. 1985; 21:173-85. http://dx.doi.org/10.1016/00137944(85)90063-3

13. Johnson $\mathrm{P}$, Zhang $\mathrm{XP}$ and Pluvinage, G. Crack growth rate in impact fatigue and in programmed variable amplitude loading fatigue. Engineering Fracture Mechanics. 1990; 37:519-525. http://dx.doi.org/10.1016/0013-7944(90)90377-S

14. Sadananda K, Vasudevan AK, Holtz RL and Lee EU. Analysis of overload effects and related phenomena. International Journal of Fatigue. 1999; 21:233-246. http:// dx.doi.org/10.1016/S0142-1123(99)00094-8

15. Wahab M, Rohrsheim G and Park J. Experimental study on the influence of overload induced residual stress field on fatigue crack growth in aluminium alloy. International Journal of Fatigue. 2007; 153: 945-951.

16. Xiaoping $\mathrm{H}$, Moan $\mathrm{T}$ and Weicheng $\mathrm{C}$. An engineering model of fatigue crack growth under variable amplitude loading. International Journal of Fatigue. 2008; 30:2-10. http://dx.doi. org/10.1016/j.ijfatigue.2007.03.004

17. Mohanty J, Verma B and Ray P. Prediction of fatigue crack growth and residual life using an exponential model: Part II (mode-I overload induced retardation). International Journal of Fatigue. 2009; 31:425-432. http://dx.doi.org/10.1016/j. ijfatigue.2008.07.018

18. Shin C and Hsu S. On the mechanisms and behaviour of overload retardation in AISI 304 stainless steel. International Journal of Fatigue. 1993; 15:181-192. http://dx.doi.org/10.1016/01421123(93)90175-P 